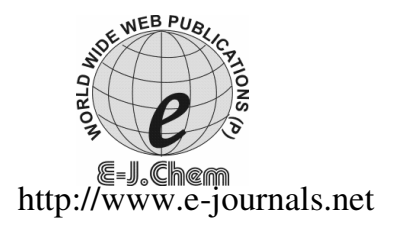

ISSN: 0973-4945; CODEN ECJHAO

E-Journal of Chemistry

2011, 8(2), 875-881

\title{
Determination of Valdecoxib in Human Plasma Using Reverse Phase HPLC
}

\author{
PRAFULLA KUMAR SAHU*, K. RAVI SANKAR and \\ M. MATHRUSRI ANNAPURNA ${ }^{\S}$ \\ *Alliance Institute of Advanced Pharmaceutical and Health Sciences \\ \#604A Aditya Trade Centre, Ameerpet \\ Hyderabad-500038, Andhra Pradesh, India \\ APL Research Centre, Aurobindo Pharma Ltd \\ Hyderabad-500072, Andhra Pradesh, India \\ ${ }^{\S}$ Roland Institute of Pharmaceutical Sciences \\ Khodasinghi, Berhampur-760010, Orissa, India \\ kunasahu1@rediffmail.com
}

Received 14 December 2009; Accepted 22 February 2010

\begin{abstract}
An RP-HPLC analytical method for estimation of valdecoxib in human plasma was developed and validated. Protein precipitation and valdecoxib extraction from plasma $(200 \mu \mathrm{L})$ was carried out by adding $800 \mu \mathrm{L}$ perchloric acid $(5 \%, \mathrm{v} / \mathrm{v}$ in water) containing nimesulide as the internal standard followed by vortex mixing and centrifugation. The supernatant $(20 \mu \mathrm{L})$ was then injected onto an ODS $\mathrm{C}_{18}(25 \mathrm{~cm} \times 4.6 \mathrm{~mm})$ column from Shimadzu. The mobile phase comprised of acetonitrile and water (35:65) with a total run time of $12 \mathrm{~min}$ and the wavelength of the detector was set at $244 \mathrm{~nm}$. The extraction recovery of valdecoxib from plasma was $>95 \%$ and the calibration curve was linear $\left(r^{2}=0.999\right)$ over valdecoxib concentrations ranging from 20 to $1400 \mu \mathrm{g} / \mathrm{mL}$ $(n=10)$. The method had an accuracy of $>92 \%$ and LOD and LLOQ of $3.58 \mu \mathrm{g} / \mathrm{mL}$ and $13.45 \mu \mathrm{g} / \mathrm{mL}$ respectively. The method reported is simple, reliable, precise, accurate and has the capability of being used for determination of Valdecoxib in clinical settings.
\end{abstract}

Keywords: Valdecoxib, RP-HPLC, Human plasma, Estimation.

\section{Introduction}

Valdecoxib is chemically designated as 4-(5-methyl-3-phenyl-4-isoxazolyl) benzenesulfonamide and is a diaryl substituted isoxazole ${ }^{1,2}$ (Figure 1), with the trade name Vx2 (Novartis) has a molecular weight of 314.36. It is commonly used as a non-steroidal 
anti-inflammatory drug (NSAID) that exhibits anti-inflammatory, analgesic and antipyretic properties indicated for oral administration, for the treatment of osteoarthritis and Rheumatoid arthritis ${ }^{3}$. Even chronic administration of valdecoxib to patients for the treatment of osteoarthritis and rheumatoid arthritis like disease would not increase the risk from cardiac arrhythmia associated with QT prolongation ${ }^{4}$. Valdecoxib is official only in the martindale extra pharmacopoeia. It acts by inhibiting prostaglandin synthesis primarily by blocking cyclo-oxygenase- $2(\operatorname{cox}-2)^{5}$. At therapeutic plasma concentration, valdecoxib does not inhibit cyclo-oxygenase $-1(\operatorname{cox}-1)^{6}$. Valdecoxib binds to the cox- 2 enzyme and there by prevents its activity in response to stimulation from cytokines. This blockade inhibits series of reaction leading to pain. Valdecoxib may inhibit the cox-2 enzyme in three stages. In the first stage the inhibitor interacts at the enzyme surface near the membrane binding region. This site is an entrance to hydrophobic channel leading to the cox-active site. The inhibitor is transported from the membrane to the cox-active site in the second stage. The third stage may be strong interaction between the phenyl sulfonamide group of valdecoxib and protein residues of the cox- 2 enzymes.

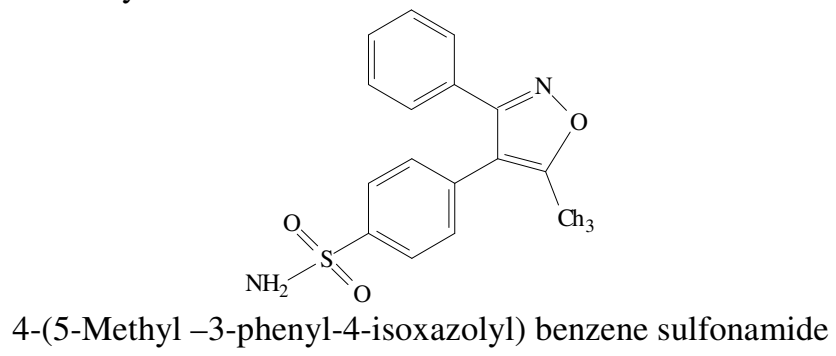

Figure 1. Chemical structure of valdecoxib

Several HPLC-UV methods have been reported for valdecoxib estimation in biological samples like human urine ${ }^{7}$, plasma ${ }^{8,9}$. Valdecoxib has analytical methods for bioequivalence studies $^{10}$, metabolite determination ${ }^{11-13}$ and estimation of formulation ${ }^{14}$, HPTLC method for simultaneous estimation in tablet dosage form ${ }^{15}$. The aim of the current study is to develop a simple, rapid and reliable method for estimation of valdecoxib in human plasma using RPHPLC technique and to validate the method according to guidelines provided by the Food and Drug Administration (FDA) ${ }^{16}$.

\section{Experimental}

Valdecoxib (99.99\% pure) and the internal standard (IS) (Nimesulide) were obtained from Exim-Pharm International, Santacruz (East), Mumbai (India). Perchloric acid (70\%, v/v) was obtained from S. D. fine- CHEM Limited, Mumbai and HPLC grade acetonitrile was purchased from E. Merck (India)Limited, worli, Mumbai. Purified de-ionized water was prepared using Milli Q50 (Millipore, Bedford, MA) water purification system. For the preparation of in-house quality controls and calibration samples, human plasma containing Sodium citrate anticoagulant was procured from local pathological laboratory

\section{Chromatographic conditions}

The determination of valdecoxib was performed using an HPLC-UV analytical system, which consists of a binary gradient HPLC with Shimadzu LC10AT and LC10AT vp series HPLC pumps, with a $20 \mu \mathrm{L}$ sample loop (manual) and a variable wavelength UV-visible detector set (SPD 10 A vp detector) at $244 \mathrm{~nm}$. Peak areas were integrated using the Shimadzu CLASS-VP version 6.12 SP1 software. Chromatographic separation of valdecoxib 
and IS was achieved using hypersil ODS C-18 (250x4.6 mm, packed with 5 micron) column. Mobile phase was filtered and degassed by passing them through $0.45 \mu \mathrm{m}$ Nylon filters (Millipore, Bedford, MA) under vacuum.

Elution of valdecoxib and its IS from the chromatographic column was carried out using a fast gradient elution technique. The composition of mobile phase was acetonitrile: T. D. Water (35: 65) comprising a total run time of 12 minutes at a flow rate of $1 \mathrm{ml} /$ minute. The analysis was carried out at ambient temperature. The Detector wavelength was set at $244 \mathrm{~nm}$. The column pressure was maintained at $210 \mathrm{kgf} / \mathrm{cm}^{2}$. For analysis, the peak area ratio of valdecoxib and the IS was used at different Valdecoxib concentrations under the current analytical condition. All calculations were performed using peak area ratios of the larger valdecoxib peak to the IS peak (peak area ratio) by the use of Microsoft Excel (MS Office, 2000).

\section{Calibration and quality control standards}

Stock solutions of valdecoxib (stock solution I: $15 \mathrm{mg} / \mathrm{mL}$ and stock solution II: $10 \mathrm{mg} / \mathrm{mL}$ ) and internal standard $(1 \mathrm{mg} / \mathrm{mL})$ were prepared in acetonitrile. It was then stored at a freezer temperature $\left(-20{ }^{\circ} \mathrm{C}\right)(\mathrm{RQFV}-265$, REMI, India) to avoid degradation of valdecoxib over the study period. A total of ten concentrations of valdecoxib including 20,40,60, 80, 100, 200, $400,800,1200$ and $1400 \mu \mathrm{g} / \mathrm{mL}$ in drug free plasma were used as calibrators. Three inhouse quality control standards (QCs), containing Valdecoxib at low $(30 \mu \mathrm{g} / \mathrm{mL})$, medium $(300 / \mathrm{mL})$ and high $(1000 \mu \mathrm{g} / \mathrm{mL})$ concentrations were also prepared in plasma and were used for assay validation. The stock solution I was used to prepare the highest calibrator $(1400 \mu \mathrm{g} / \mathrm{mL})$ and quality control sample $(1000 \mu \mathrm{g} / \mathrm{mL})$, while the remaining calibrators and quality control samples were prepared from stock solution II. Aliquots of the internal standard stock solution were diluted in $5 \%(\mathrm{v} / \mathrm{v})$ perchloric acid to produce a working strength $(20 \mu \mathrm{g} / \mathrm{mL})$ internal standard solution. This was also used as precipitating reagent for plasma samples. Aliquots of the calibrators, quality control samples and reference standard solutions were stored at $-20{ }^{\circ} \mathrm{C}$ until use. All calibrators or quality control samples were injected in triplicates.

\section{Sample preparation}

Frozen calibrators and quality control standards were thawed at $37{ }^{\circ} \mathrm{C}$ using a thermostatic shaking water bath (Remi water bath shaker, Mumbai, India). Aliquots of the plasma samples $(200 \mu \mathrm{L})$ were added to $1.5 \mathrm{~mL}$ micro centrifuge tubes (Eppendorf, Germany). To all samples, $800 \mu \mathrm{L}$ of $5 \%$ perchloric acid containing internal standard $(10 \mu \mathrm{g} / \mathrm{mL})$ was added. This was vortex mixed for $3 \mathrm{~min}$ and sonicated for $5 \mathrm{~min}$ in an ultrasonic water bath. The tubes were then centrifuged for $10 \mathrm{~min}$ in a micro centrifuge unit (High speed Remi refrigerated Centrifuge, India). The resulting supernatant was decanted and $25 \mu \mathrm{L}$ of this supernatant was injected onto the analytical column, previously equilibrated with acetonitrile and water at ratio of 35: $65(\mathrm{v} / \mathrm{v})$.

\section{Assay validation}

All validation steps were conducted following FDA guidelines ${ }^{16}$. To evaluate specificity, blank samples of plasma containing no valdecoxib or IS were analyzed to check for the presence of interfering peaks at the elution time of valdecoxib and IS. Furthermore, to avoid possible chromatographic interference by other drugs no medications were allowed to the health volunteers for two weeks prior to the study. The sensitivity of the analytical technique was expressed as the lower limit of quantification (LLOQ) which is the minimum plasma 
concentration of valdecoxib that can be quantitatively determined with peak height to base line ratio of at least 10:1 and the limit of detection (LOD) as peak height to base line ratio of $3: 1$. The analytical recovery of valdecoxib was assessed by comparing the peak area ratio of QCs with the peak area ratio (analyte peak area/IS peak area) of the reference standards prepared in methanol. The closeness of mean test results obtained by the method to the actual concentration of the analyte and the degree of agreement among the individual results for multiple analytical runs of the same sample was taken as the accuracy and precision, respectively. To evaluate stability, aliquots of QCs were subjected to three cycles of freeze and thaw (freezing for $24 \mathrm{~h}$ at $-20{ }^{\circ} \mathrm{C}$ and thawing unassisted at room temperature). For short-term stability test, the aliquots of the QCs were thawed at room temperature and kept at this temperature for $8 \mathrm{~h}$ (the duration of analysis for a typical batch) before analysis.

\section{Patient samples}

The protocol was approved by institutional ethical committee and written informed consent was obtained from each patient. After approximately $12 \mathrm{~h}$ of fasting (overnight), valdecoxib $20 \mathrm{mg}$ (Vx2, Novartis) were administered to all the volunteers with $100 \mathrm{~mL}$ of water. Food and drinks were not permitted for $3 \mathrm{~h}$ after drug administration. After $3 \mathrm{~h}$ a standard breakfast was given to the volunteers. The subjects were maintained in a sitting position for the first $3 \mathrm{~h}$ after drug administration and were confined to the laboratory during the study days.

The subjects were divided into two groups at random and the study was conducted in a crossover design allowing washout period of seven days between each treatment. On the study day, a cannula was inserted into the antecubital vein of each arm, and a baseline blood sample was drawn.

Blood samples for valdecoxib analysis were drawn from the antecubital vein of the arm in $2 \mathrm{~mL}$ blood before valdecoxib dose and at approximately $0.5,1,2,2.5,3,4,8,12$, 24,30 and $36 \mathrm{~h}$ post dose. The blood samples were centrifuged for 25 minutes at 2500 $\mathrm{rpm}$ and room temperature; plasma was separated and stored under frozen condition $\left(-20^{\circ} \mathrm{C}\right)$ until analysis.

\section{Results and Discussion}

A typical blank plasma chromatogram is shown in Figure 2(a) and Figure 2(b) illustrates chromatogram of valdecoxib and IS in extracted plasma sample from a representative patient sample. Valdecoxib was eluted at 11.250 , whereas the IS eluted at $8.783 \mathrm{~min}$ and no interfering peaks were observed at the time of valdecoxib peaks or the IS. The specificity of the method was tested by analyzing plasma samples before the administration of valdecoxib dose. Valdecoxib LOD and LLOQ were found to be 3.58 and $13.45 \mu \mathrm{g} / \mathrm{mL}$, respectively. The assay was linear over valdecoxib concentration range of $20-1400 \mu \mathrm{g} / \mathrm{mL}$ with an average correlation coefficient $\left(r^{2}\right)$ of $0.99(n=10)$. The accuracy of the estimated valdecoxib concentration was more than $92 \%$ at three QC concentrations (Table 1). The precision expressed as inter-day coefficient of variation (CV\%) ranged from $0.92 \%$ to $2.15 \%$ (Table 1) and the intra-day CV\% ranged from $0.35 \%$ to $2.7 \%$.

The liquid-liquid extraction method for extraction of valdecoxib from plasma samples had an average recovery ranging from $99.64 \pm 0.04 \%$ to $100.04 \pm 0.047 \%$ for low to high QC standards. The recovery was reproducible over six replications performed over 6 different days. 

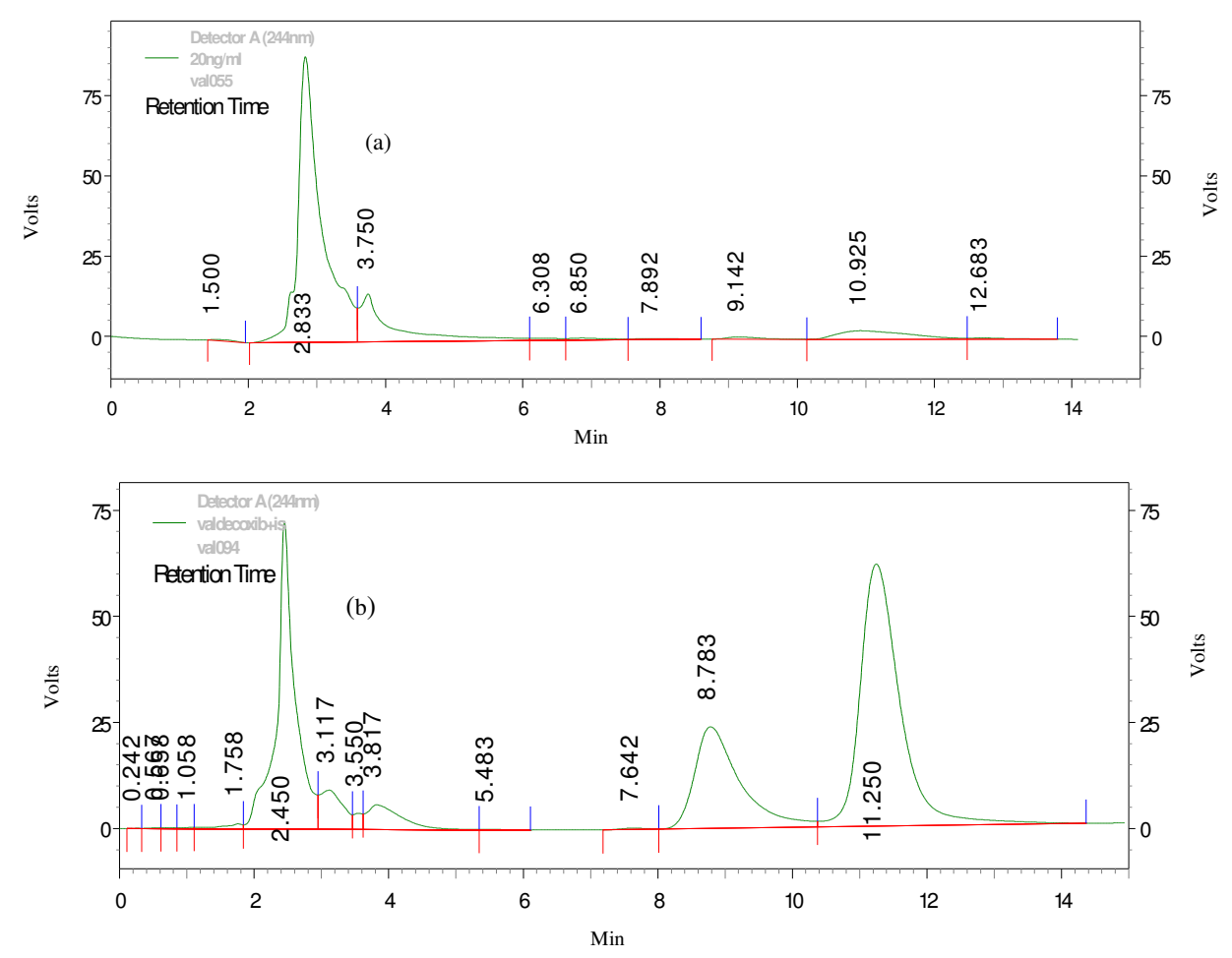

Figure 2(a). Chromatogram of valdecoxib free (blank) plasma (Retention Time: $2.833 \mathrm{~min}$.) Figure 2(b). Chromatogram of an extracted plasma sample from a drug recipient containing valdecoxib $(150 \mu \mathrm{g} / \mathrm{mL})$ along with internal standard $(50 \mu \mathrm{g} / \mathrm{mL})$, [Retention Time:8.783 and 11.250 minutes for internal standard and valdecoxib respectively]

Table 1. Precision and accuracy data for valdecoxib

\begin{tabular}{ccccc}
\hline \multirow{2}{*}{ Samples } & $\begin{array}{c}\text { Actual } \\
\text { Concentration, } \mu \mathrm{g} / \mathrm{mL}\end{array}$ & $\begin{array}{c}\text { Observed } \\
\text { Concentration (Mean } \pm \text { S.D) }\end{array}$ & $\begin{array}{c}\text { Accuracy, } \\
\%\end{array}$ & $\begin{array}{c}\text { Inter-day } \\
\text { Precision, \%CV }\end{array}$ \\
\hline QC 1 & 30 & $27.8 \pm 0.6$ & 92.8 & 2.15 \\
QC 2 & 300 & $294.4 \pm 3.8$ & 98.13 & 1.29 \\
QC 3 & 1000 & $1000.37 \pm 9.3$ & 100.03 & 0.92 \\
\hline
\end{tabular}

The data represent the mean of the assay accuracy and precision values obtained for eight sets of standard curve and QC samples. QC: quality control samples. The concentration of valdecoxib in freeze-thaw and short term stability evaluation were not significantly different from the fresh calibrators. The accuracy for the QC samples ranged from $94 \%$ to $101 \%$ and $97 \%$ to $101 \%$ after the freeze-thaw stability and short-term stability testing, respectively.

(Figure 3) depicts valdecoxib concentration versus time profile from three representative recipients. The mean \pm S.D. of all concentrations measured between 0.5 and $36 \mathrm{~h}$ post administration of valdecoxib was $190.8 \pm 26.62 \mu \mathrm{g} / \mathrm{mL}$ (concentration range: $29-409 \mu \mathrm{g} / \mathrm{mL}$ ). The maximum concentration $\left(C_{\max }\right)$ measured at $3 \mathrm{~h}$ after dose was $347.7 \pm 57.74 \mu \mathrm{g} / \mathrm{mL}$ ranging from 294.3 to $409.0 \mu \mathrm{g} / \mathrm{mL}$ (Table 2$)$. The minimum concentration $\left(C_{\min }\right)$ measured at $36 \mathrm{~h}$ post dose was $44.87 \pm 16.76 \mu \mathrm{g} / \mathrm{mL}$ (range: $29-62.41 \mu \mathrm{g} / \mathrm{mL}$ ). 


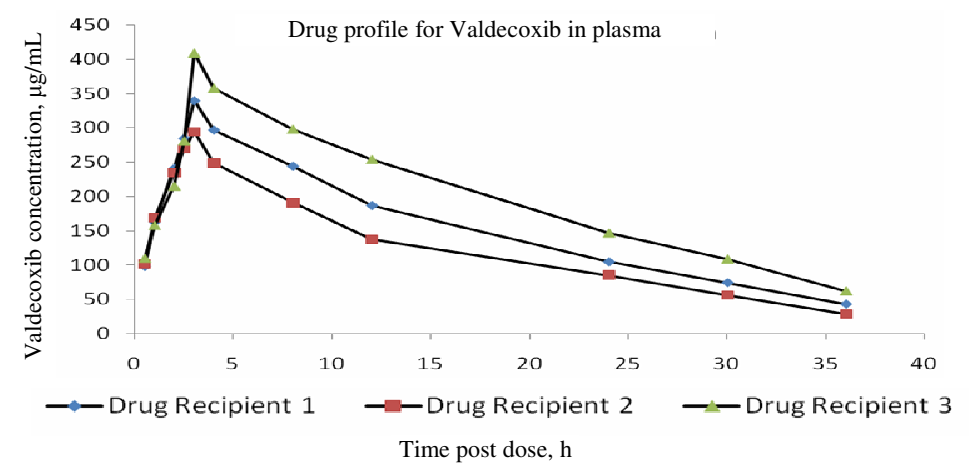

Figure 3. Valdecoxib concentration $v s$. time profile from three drug recipients

Table 2. Pharmacokinetic parameters

\begin{tabular}{ccc}
\hline Pharmacokinetic parameters & Reported & Observed \\
\hline $\mathrm{T}_{\max }$ & $2.3 \mathrm{~h}$ & $3 \mathrm{~h}$ \\
$\mathrm{C}_{\max }$ & $320 \mu \mathrm{g} / \mathrm{mL}$ & $347.7 \pm 57.74 \mu \mathrm{g} / \mathrm{mL}$ \\
$\mathrm{T}_{1 / 2}$ & $8-11 \mathrm{~h}$ & $12 \mathrm{~h}$ \\
$\mathrm{AUC}_{0-\mathrm{t}}$ & $\mu$ & $5478.538 \mathrm{~h} . \mu \mathrm{g} / \mathrm{mL}$ \\
$\mathrm{AUC}_{0-\infty}$ & $\mu$ & $6228.186 \mathrm{~h} . \mu \mathrm{g} / \mathrm{mL}$ \\
\hline
\end{tabular}

Considering no commercial methods are currently available for the estimation of Valdecoxib in biological fluids, a rapid, precise and specific method for determination of Valdecoxib in human plasma is required. In the current study, we report a simple, rapid and reliable RP-HPLC analytical method for the estimation of valdecoxib using a commercially available internal standard. The method comprises of a simple protein precipitation step using perchloric acid followed by the injection of the supernatant onto the analytical column. The extraction process was efficient as the recoveries of both valdecoxib and the IS were more than 99\%. Using a fast gradient elution technique, both valdecoxib and IS were eluted from the column with minimum interfering peaks. In the current study the LLOQ was found to be $13.45 \mu \mathrm{g} / \mathrm{mL}$ with a peak height to baseline noise ratio of 10:1. In addition in our own clinical study, the lowest observed concentration of valdecoxib at $36 \mathrm{~h}$ after the dose was approximately $29 \mu \mathrm{g} / \mathrm{mL}$ that is well within the dynamic concentration range of our HPLC method. The robustness of the method makes it easy for an operator to learn the technique quickly and to generate reproducible results. The method indeed is very economical.

In conclusion a simple, robust, precise and reproducible method is developed for determination of valdecoxib in human plasma using a commercially available internal standard. The method was then validated according to the FDA guidelines set forth for the bioanalytical method validation for human studies ${ }^{16}$.

\section{Conclusion}

The proposed methods were found to be simple, precise, accurate and rapid for determination of valdecoxib from pure and its dosage forms. The mobile phase is simple to prepare and economical. The sample recoveries in all formulations were in good agreement with their respective label claims and they suggested non - interference of formulation excipients in the estimation. Hence, thus can be easily and conveniently adopted for routine analysis of valdecoxib in pure form and its dosage forms and can also be used for dissolution or similar studies. 


\section{References}

1. Budavari S, Eds., In; The Merck index, $12^{\text {th }}$ Edn., Merck \& Co., Inc., Whitehouse Station, NJ, 1994.

2. Sean C Sweetman, Eds., In; Martindale, The Extra Pharmacopoeia, $33^{\text {rd }}$ Edn., The Pharmaceutical Press, London, 2002, 90.

3. Ormrod D, Wellington K and Wagstaff A J, Drugs, 2002, 62, 2059.

4. Nenad Sarapa, Margaret R Brito, Barbara Cotton, Steven R Cox, Steven F Francom, Na Jin, Emery D Polasek, Stephen M Sainati, Sharon L Crosby-Sessoms and Joseph C Fleishaker Sarapa, J Clin Pharmacol., 2003, 43, 974-982.

5. Fitzgerald G A and Patranoc, N Engl J Med., 2001, 345, 433.

6. Gierse J K, Koboldt C M, Walker M C, Seibert K and Isakson P C, Biochem J., 1999, 339(3), 607-614.

7. Zhang J Y, Fast D M and Breau A P, J Chromatogr B Analyt Technol Biomed Life Sci., 2003, 785(1), 123-134.

8. Ramakrishna N V S, Vishwottam K N; Wishu S and Koteshwara M, J Chromatogr B Analyt Technol Biomed Life Sci., 2004, 802(2), 271.

9. Sane R T, Menon S, Deshpande A Y and Jain A, Chromatogr., 2005, 61(3-4), 137-141.

10. Mandal U, Jayakumar M, Ganesan M, Nandi S, Pal T K, Chakraborty M K, Roy Chowdhary A. and Chattoraj T K, Indian Drugs, 2004, 41, 59.

11. Zhang J.Y, Fast D.M and Breau, A.P, J Pharm Biomed Anal., 2003, 33, 61.

12. Werner U, Werner D, Hinz B, Lanbrecht C and Brune K, J Biomed Chromatogr., 2004, 19, 113.

13. Zhang J V, Fast D M and Breau A P, J Chromatogr B Anal Technol Biomed Life Sci., 2003, 785, 123.

14. Sutariya V B, Rajashree M, Sankalia M G. and Priti P, Indian J Pharm Sci., 2004, 93, 112 .

15. Gandhimathi M, Ravi T K, Shukla Nilima and Sowmiya G, Indian J Pharm Sci., 2007, 69(1), 145-147.

16. Shah V P, Midha K K, Findlay J W A, Hill H M, Hulse J D, McGilveray I J, McKay G, Miller K J, Patnaik R N, Powell M L, Tonelli A, Viswanathan C T and Yacobi A, Pharm Res., 2000, 17, 1551-1557. 


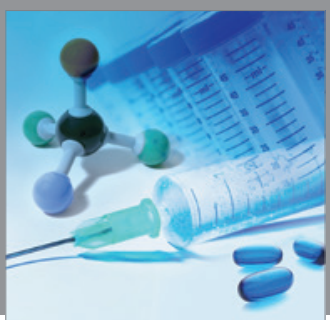

International Journal of

Medicinal Chemistry

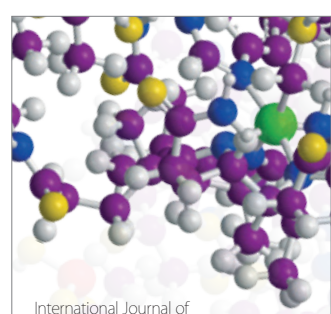

Carbohydrate Chemistry

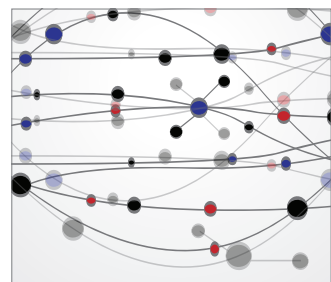

The Scientific World Journal
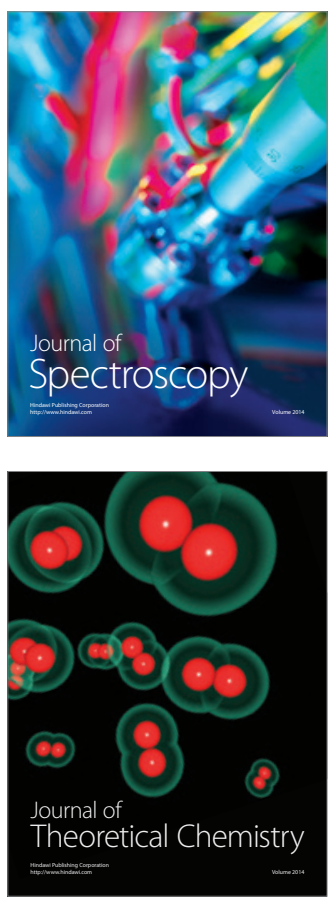
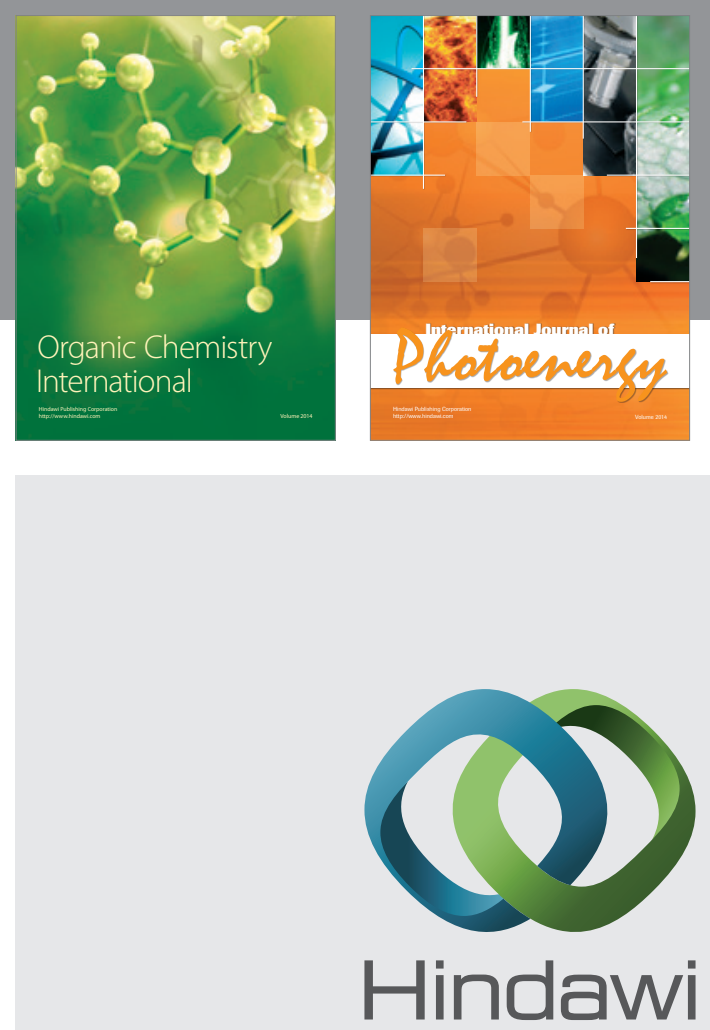

Submit your manuscripts at

http://www.hindawi.com
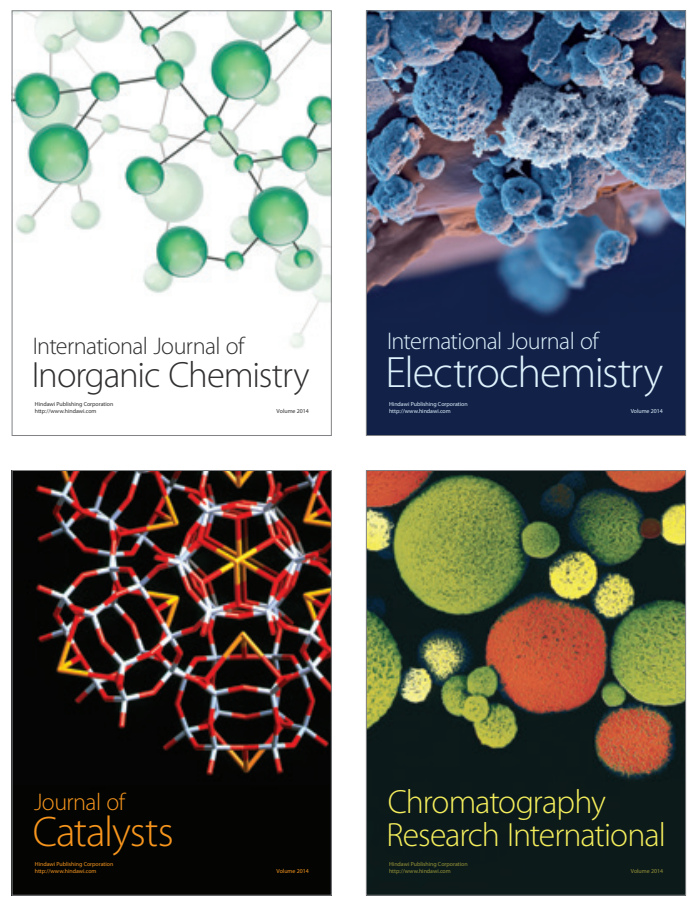
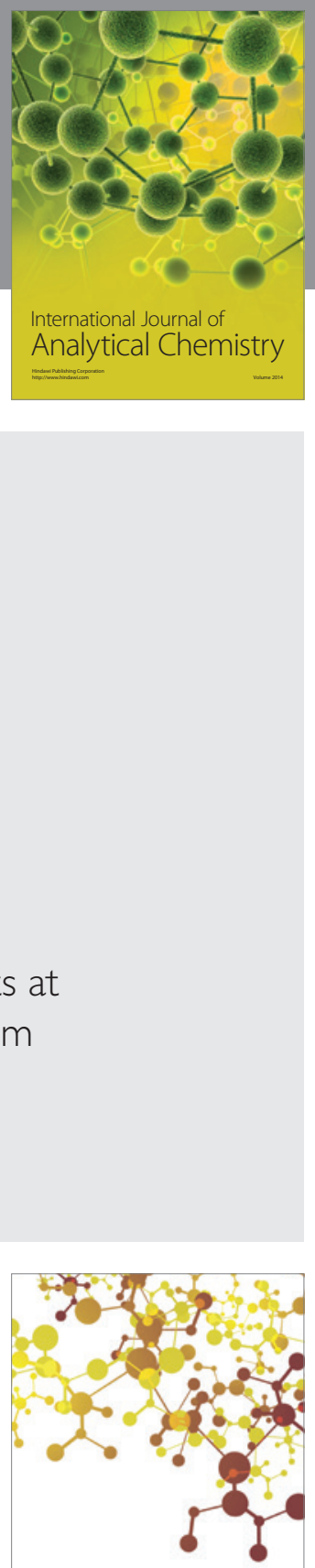

Journal of

Applied Chemistry
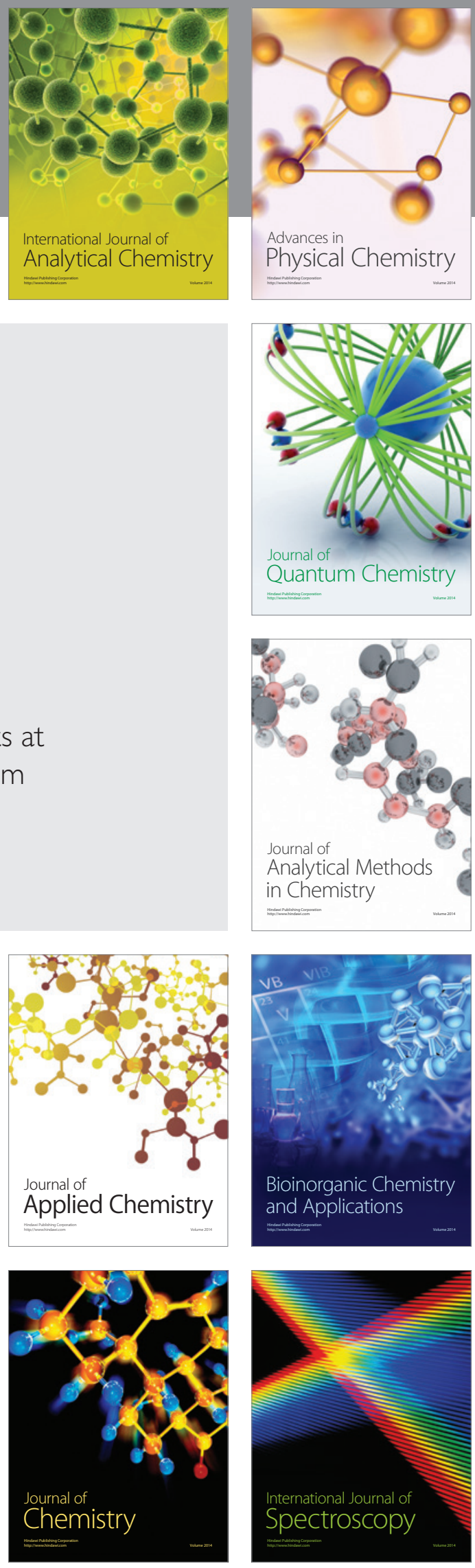